\section{$\underset{\substack{\text { hommes } \\ \text { \& migrations }}}{ }$}

\section{Hommes \& migrations}

Revue française de référence sur les dynamiques

migratoires

$1314 \mid 2016$

Migrations chinoises et générations

\title{
La Marseillaise et cætera
}

Jérémy Beschon

\section{(2) OpenEdition \\ Journals}

\section{Édition électronique}

URL : http://journals.openedition.org/hommesmigrations/3652

DOI : 10.4000/hommesmigrations.3652

ISSN : 2262-3353

\section{Éditeur}

Musée national de l'histoire de l'immigration

\section{Édition imprimée}

Date de publication : 1 avril 2016

Pagination : 133-136

ISBN : 978-2-919040-35-3

ISSN : $1142-852 X$

\section{Référence électronique}

Jérémy Beschon, « La Marseillaise et cætera », Hommes \& migrations [En ligne], 1314 | 2016, mis en ligne le 19 septembre 2016, consulté le 15 septembre 2020. URL : http://journals.openedition.org/ hommesmigrations/3652 


\section{LA MARSEILLAISE ET CAETERA}

Par JÉRÉMY BESCHON, auteur, metteur en scène, collectif Manifeste Rien.

$L$ a Marseillaise et cætera est une pièce de théâtre qui aborde la question des symboles nationaux et de l'histoire de l'immigration. Les incidents relatifs à l'hymne et au drapeau n'ont rien de nouveau. Le premier épisode a eu lieu à Marseille, en 1881. Des travailleurs d'origine italienne ayant sifflé La Marseillaise sont pourchassés par une partie de la population locale pendant une semaine. Dès cette époque, les journalistes mentionnent que ces immigrés forment une "nation dans la nation" refusant de s'intégrer dans la société française.

\section{Une pièce puisant dans trois sources complémentaires}

La pièce de théâtre s'appuie sur trois sources complémentaires pour traiter la problématique des identités et de la nation : une recherche historique menée par Gérard Noiriel(1) ; une étude de la presse contemporaine via Internet; et une enquête ethnographique auprès d'habitants des quartiers populaires de Marseille. Cette enquête a porté sur l'identité, la mémoire et la nation. Elle a révélé de multiples contradictions entre fierté et honte des origines, entre rejet du stigmate et son intériorisation ${ }^{(2)}$. L'écoute des entretiens a été précieuse durant l'écriture de la pièce en 2014. Ils ont été transposés dans les dialogues de la pièce, ou bien se sont inscrits dans la bande son, sous forme d'interférences ou de bribes puisées hors de l'illusion scénique.
La Marseillaise et cætera se présente sous la forme d'une comédie de moeurs qui mêle les sciences sociales et la science-fiction. Trois espaces temps s'imbriquent, s'affrontent et se répondent dans la pièce. Les soucoupes volantes côtoient la sociohistoire ; les ancêtres rencontrent leurs descendants ; les symboles nationaux éclairent l'histoire de l'immigration. Car la pièce traduit le fait que, de 1881 à nos jours, une même condamnation des classes privilégiées s'abat sur les classes populaires. Ces dernières ne sont pas pour autant exemptes de xénophobie, un rejet de l'altérité face à l'étranger, à l'immigré, mais également un rejet de leur propre altérité.

\section{Prologue sur la frontière}

Le personnage du prologue est une migrante subsaharienne coincée à Ceuta au Maroc, devant les grilles de l'Europe. Elle vit là, à la frontière. Celle qui ne pénètrera jamais le territoire français est chargée de commencer la pièce. L'externalisation de la frontière symbolisée par la présence de cette femme hors du sol français, représente un hors champs que le public est amené à partager. C'est l'espace d'une attente sans fin. La femme y mentionne l'extrême violence des carabiniers. Elle $n$ 'arrive pas à croire que des européens, dont on lui donné une toute autre image, puissent si mal la traiter. Elle se demande "si ces gens là sont de vrais blancs ou bien des arabes naturalisés(3)". Dans l'interprétation de cette migrante, la pièce 


\section{REPÉRAGE}

ne marque aucune neutralité. La comédienne est noire et prend un accent qui créolise le français Plusieurs niveaux de perception s'offrent alors à la sagacité des spectateurs qui s'amusent et s'indignent, compatissent et s'inquiètent. Un musicien entre enfin sur scène, s'assoit devant son clavier et chante mélancolique: "Ghost in Républic". "Fantômes de la république?" s'interroge la femme, "c'est sans doute un message pour vous". Elle souhaite un bon spectacle au public, se retourne et change de personnage.

\section{Les Grimaldi, un couple pris par surprise}

Un vaisseau spatial entre sur scène... II fait partie du Centre des mémoires refoulées, une organisation magique et mémorielle qui doit intervenir chez un couple, les Grimaldi. Ce couple vient d'acheter un pavillon en banlieue parisienne. Il est heureux et aussi inquiet par les travaux à effectuer dans la maison acquise grâce à un crédit sur trente ans. Dans leur salon, la télévision allumée ressasse sans relâche les discours sécuritaires alimentés par l'actualité des guerres en Orient, des attentats islamiques, des trafiques et violences dans les banlieues.

Le téléphone sonne. La direction des ressources humaines de l'entreprise où travaille Stan Grimaldi lui impose de recevoir Alfred Schweinsteiger, le nouveau directeur commercial. La seule information dont dispose Stan est que ce dernier est alsacien. Quelques secondes plus tard, la sonnette de l'entrée retentit. Stan ouvre la porte à un homme noir qui se tient sur le perron :c'est Alfred Schweinsteiger. Le quiproquo est vite résolu mais un malaise plus profond concerne une différence de classe sociale. Alfred appartient à la petite bourgeoisie alors que Stan porte les traces de ses origines plébéiennes. Heureusement le match de football France-Algérie est là. Tous deux vont d'un commun accord le regarder. L'excitation est à son comble lorsque La Marseillaise est "copieusement sifflée" par le public du stade. Excédé par la surenchère des commentaires journalistiques et politiques à propos de ce sifflement, Stan finit par lâcher: "C'est normal quand on voit cette équipe plein d'Arabes et de Noirs!" Le directeur commercial offusqué s'en va en claquant la porte. Adieu la promotion! Comment payer maintenant le crédit ? Stan furieux met un grand coup de tête dans son poste de télévision. Du plasma de l'écran fendu sort un conteur, un agent envoyé par le Centre des mémoires refoulées.

\section{Les vêpres marseillaises et la création de l'espace public}

Le conteur rappelle à Stan Grimaldi, encore sous le choc, que La Marseillaise a été sifflée pour la première fois à Marseille. Le patronat avait engagé de la main-d'oeuvre italienne bon marché, suscitant des tensions et des rivalités avec les autres ouvriers au cours de l'année 1881. C'est également la toute première année de la liberté de la presse qui donne naissance à une industrie ; "papier et plomb pour un pays à l'unisson !" Les notables de la Troisième République veillent en effet à leurs intérêts économiques en contrôlant l'opinion publique naissante. À l'époque, la France et l'Italie sont en guerre pour la conquête de la Tunisie. Le 17 juin 1881, l'armée française revient victorieuse de Tunis et défile en tenue d'apparat rue de la République à Marseille. 15 ooo personnes hurlent à leurs fenêtres: "Vive l'armée, vive la France, vive la République!" Lorsque le cortège passe sous le balcon du Cercle national italien, les membres de ce dernier se penchent et sifflent à la balustrade. L'adjoint au Maire monte au balcon du Cercle national italien, arrache le drapeau italien et demande aux personnes de se disperser. Mais la foule s'y 
refuse, provoquant une chasse aux Italiens qui va durer plusieurs jours. Jusque-là, les rixes meurtrières entre ouvriers n'intéressaient pas les notables. Cette fois-ci, l'affaire reçoit un écho national par la presse qui est en train de nationaliser l'espace public. Pour la première fois, la Une des journaux emploie le mot "immigration". Ce sont d'ailleurs les journaux de l'élite républicaine qui insistent sur l'importance politique de cet événement, établissant le lien entre l'ennemi intérieur et l'ennemi extérieur. Le conflit local devient le symptôme d'une nouvelle maladie : le virus de l'actualité.

\section{Mémoire individuelle contre rationalisation}

Lorsque Stan Grimaldi se réveille, il se remémore avec fierté la vie de ses ancêtres italo-marseillais qui étaient présents le 17 juin 1881 rue de la République à Marseille. Ces derniers n'ont pas sifflé La Marseillaise; Stan en est persuadé. Ils ont eu honte de leurs frères italiens. Ils ont remercié la France qui les avaient arrachés à la misère, leur avait offert l'instruction, grâce à la loi de 1881 qui crée l'école gratuite, laïque et obligatoire. Stan n'a pas donc entendu le conteur de la même oreille que le public. La première intervention du Centre des mémoires refoulées est un échec.

Ne pouvant rien obtenir de Stan, dont les blagues racistes empirent, le Centre des mémoires refoulées décide de s'adresser à sa femme, Françoise. Celle qui pensait être d'origine arienne, découvre lorsqu'elle est face à sa grand-mère et à son arrière-arrière grand-mère, qu'elle est d'origine russe, juive et allemande. Mais, de nouveau, la mécanique émotionnelle échappe au Centre des Mémoires Refoulées. Les ancêtres de Françoise se révèlent aussi incontrôlables que contradictoires. L'arrière-arrière grand-mère revit la perte de son petit frère lors de la Première Guerre mondiale alors que le salon des Grimaldi se transforme en tranchée boueuse. Ce petit frère, naturalisé par la loi de 1889, meurt à 21 ans en se battant contre des Allemands, son peuple d'origine.

Le conteur propose "un retour en arrière avant la der des der". Les républicains, qui ont concocté la loi de naturalisation en 1889 , pensaient régler le problème de l'assimilation des étrangers. Mais, en naturalisant les enfants des étrangers, "ils ont rempli les rangs de l'armée avec du sang neuf, mais surtout créé une machine infernale" car, comme l'a écrit Gérard Noiriel, toute politique fondée sur l'exploitation de faits divers peut être contestée au nom d'autres faits divers. Lors du scandale des vêpres marseillaises en 1881, qui avaient inauguré l'axe du mal (germano-transalpin), les républicains avaient dénoncé toute la communauté italienne à partir du comportement d'un nombre restreint d'individus. Et, huit ans plus tard, "retour de manivelle" nous dit le conteur! Les conservateurs catholiques, exclus du pouvoir depuis peu, reprennent à leur compte la rhétorique républicaine, pour démontrer que cette législation de 1889 est une aberration, "un nid d'espions". Cette fois-ci, ce sont les conservateurs catholiques qui vont exploiter la rubrique criminelle de la presse, en insistant sur l'origine des malfaiteurs naturalisés et juifs. Pour les conservateurs, ce n'est pas le droit qui fait le Français, c'est l'origine. La bataille entre le national et l'étranger est lancée avec deux grands pôles : le national sécuritaire d'un côté (les conservateurs) et le social humanitaire de l'autre (les républicains). "La politique spectacle donne alors sa première représentation et l'antisémitisme aura le premier rôle..."

\section{Retour à Marseille...}

Stan Grimaldi a été licencié, tout comme Alfred Schweinsteiger ; "c'est économique". La perte d'emploi de Stan n'est donc pas due, comme il le 


\section{REPÉRAGE}

pensait, à leur altercation lors du match. La multinationale, qui a racheté l'entreprise, s'est simplement débarrassée d'un personnel trop onéreux. Le couple Grimaldi doit vendre son pavillon et veut s'installer à Marseille qui fourmille de startup en cette année $2013^{(4)}$. Il veut acheter un nouvel appartement, rue de la République. Mais les rues sont étrangement désertes. II semblerait que la rénovation urbaine ait expulsé les locataires dont Françoise entend les voix. D'ailleurs, une vieille dame interrompt la visite de l'agent immobilier en les injuriant et en dénonçant haut et fort les démarches frauduleuses de la ville et des multinationales. Elle est un vestige encore vivant du quartier, restée-là, seule, "à la frontière de la ville nouvelle".

\section{Une histoire à tiroirs}

Ces différentes scènes sont zébrées par les voix des quartiers populaires que l'on entend habituellement qu'à travers le prisme des médias. Ces voix interfèrent sur scène: dans le téléviseur des Grimaldi, dans le vaisseau du Centre des mémoires refoulées, dans la rue de la République... Elles expriment les points de vue des interviewés de l'enquête auprès des habitants de Marseille. Ceux-ci, en majorité des enfants d'immigrés algériens et comoriens, partagent un grand nombre de points communs avec la famille franco-italienne de Stan et la famille franco-russe, juive, allemande de Françoise, tout en dénonçant ce que les deux principaux personnages de la pièce ont oublié : la souffrance journalière des discriminations ; leur nationalité française dont ils ne comprennent pas les remises en cause ; la revendication de leur culture d'origine qui s'est perdue dans la normalisation ; la révolte contre des discours stigmatisant mais doublée d'une intériorisation de ceux-ci ; le territoire urbain qui les isole...
Dans ce travail, la dramaturgie classique cède le pas à l'histoire à tiroirs, ainsi qu'à l'art du conteur qui incarne la mauvaise conscience de son temps. Le Conteur déclare: "Hier comme aujourd'hui, médias et classes supérieures condamnent les lèvres qui sifflent, les voix qui jurent, mais jamais celles qui soufflent le texte... Hier comme aujourd'hui, les élites condamnent le bras qui frappe, mais jamais celui qui l'arme, et quand la main vengeresse frappe l'innocent, elles crient au scandale : 'Regardez donc ces vandales!'Si jadis la Nation s'est repue du sang des pauvres tout nouvellement français, il semblerait qu'aujourd'hui les frontières soient tout autres : là-bas au Maroc, coincés aux portes de l'Europe, comme ici, dans les plis de vos villes entre l'oubli et le mépris."

Cette pièce se joue dans les théâtres, les écoles, les bibliothèques, les musées afin de partager les outils de l'analyse critique des sciences sociales. Sur un plateau nu, un trio de comédiens interprètent les différents personnages, mais les comédiens jouent également les lieux où se déroulent les actions, tel le vaisseau spatial du Centre des mémoires refoulées, ou bien encore les objets, telle la télévision des Grimaldi. Tout en restant dans une recherche de l'épure, ils libèrent leur potentiel physique et créatif et trouvent ainsi l'écho le plus direct auprès du spectateur. Ils mêlent les archétypes du divertissement contemporain aux techniques traditionnelles du théâtre que sont la commedia dell'arte, le conte, le mime. Le musicien accompagne le jeu des comédiens par une correspondance d'émotions. Si sa partition d'électro-live invite au voyage, c'est aussi lui qui transmet les interférences et les témoignages du réel qui brouillent et éclairent à la fois la fiction. I 